\title{
Analysis Thresholding Sauvola pada Background Subtraction untuk Deteksi Objek Bergerak
}

\author{
Elindra Ambar Pambudi ${ }^{1}$, Abid Yanuar Badharudin ${ }^{2}$, Dimara Kusuma Hakim ${ }^{3}$ \\ 1,2,3 Universitas Muhammadiyah Purwokerto \\ e-mail: ${ }^{1}$ elindraambarpambudi@ump.ac.id, \\ 2zaidsoft.indonesia@gmail.com, \\ ${ }^{3}$ dimarakusumahakim@gmail.com
}

\begin{abstract}
Abstrak
Metode segmentasi kebanyakan digunakan dalam teknik pengolahan citra yang berkaitan dengan deteksi objek bergerak. Segmentasi pada objek bergerak sangat penting untuk menentukan proses selanjutnya berupa pengenalan atau klasifikasi. Metode yang paling umum digunakan dalam teknik-teknik segmentasi adalah metode pengambangan. Metode pengambangan memiliki fungsi merubah citra grayscale menjadi citra biner. Metode pengambangan dibagi menjadi dua yaitu global dan lokal. Pada penelitian kali ini akan mencoba menggunakan salah satu metode pengambangan lokal adaptif yaitu sauvola. Sauvola merupakan improvisasi dari niblack. Sauvola akan digunakan sebagai nilai ambang dari background subtraction. Garis besar dari metode yang diusulkan dalam penelitian ini adalah ekstraksi frame, inisialisasi background, preprocessing, background subtraction, thresholding sauvola, pemberian masking, jalankan frame secara berurutan. Hasil terbaik rata-rata MSE dan PSNR dari penelitian ini adalah 0.0011 dan 53,6653. Berdasarkan nilai rata-rata MSE dan PSNR maka dapat disimpulkan pengambangan dengan sauvola mendapat hasil cukup baik dan layak digunakan sebagai metode segmentasi berbasis pengambangan untuk mendukung background subtraction.
\end{abstract}

Kata kunci: sauvola, pengambangan, subtraction, deteksi objek bergerak

\begin{abstract}
Segmentation method mostly used in image processing technique that related to moving object detection. Segmentation in moving object detection is essential problem to determine next process, for example, classification or detection. The most common method on segmentation techniques is thresholding. Thresholding method has a function to convert grayscale image to to binary image. Thresholding divided to be global and local threshold. In this research, we use the one of the adaptive local thresholding techniques that is sauvola. Sauvola is improvement of niblack algorithm. Sauvola used as threshold value of background subtraction. The outline of proposed method in this research is extraction frame, inisialitation background, preprocessing, background subtraction, sauvola, masking process, running frame sequentially. In this research, The best average result MSE and PSNR of several videos obtained 0.0011 and 53,6653. Based on MSE and PSNR value conducted therefore the conclusion of this research is sauvola thresholding has got good result and quite appropriate as one of segmentation method based on thresholding to support background subtraction.
\end{abstract}

Keywords: sauvola, thresholding, subtraction, moving object detection

\section{Pendahuluan}

Deteksi objek bergerak umum digunakan dan sangat penting dalam lingkup penelitian pemrosesan video atau visi komputer. Deteksi objek banyak dihubungkan dengan monitoring ataupun keamanan.
Deteksi objek bergerak berkaitan erat dengan teknik pengolahan cita. Dalam penelitian ini akan memanfaatkan algoritma background subtraction. Penggunaan algoritma background subtraction didasari pada paper (Das \& Saharia, 2014)] menerangkan bahwa algoritma ini memiliki kemampuan adaptif yang tinggi yang berarti 
penyesuaian diri perubahan background lebih cepat dibandingkan metode-metode lain yang sejenis. Salah satu teknik pada pengolahan citra (Image Processing) yaitu teknik pengambangan (Thresholding).

Pengambangan adalah proses pembuatan citra biner dari citra grayscale dengan merubah keseluruhan piksel yang memiliki nilai nol saat dibawah nilai ambang dan satu saat diatas nilai ambang. Terdapat dua pendekatan metode pengambangan yaitu global threshold dan lokal threshold ( $\mathrm{N}$ \& S, 2016). Beberapa penelitian mengenai pengambangan lokal adaptif berhubungan dengan pengolahan citra.

Julian Ghaye memaparkan tentang penjelajahan teknik-teknik adaptif global and local segmentasi untuk lab-on-chip sistem pengamatan nutrisi (NutriChip) (Ghaye et al., 2013). Dalam penelitian tersebut digunakan threshold global (otsu,tpoint) dan lokal (sauvola) yang dikombinasi dengan Morfologi matematika Top Hat (THMM) filter. Metode tersebut digunakan untuk mengklasifikasikan citra-citra yang berpendar.

teknik pengambangan lokal adaptif memanfaatkan rata-rata lokal dan standar deviasi (N \& S, 2016). Dalam penelitianya membandingkan niblack dan sauvola diimplementasikan pada citra medis. Hasil dari artikel tersebut adalah niblack lebih baik dari sauvola berdasarkan perhitungan PSNR dan koefisien persamaan jaccard.

Kalaiselvi menerangkan pada papernya mengenai perbandingan metodemetode threshold dengan kasus menemukan pengambangan yang cukup bagus untuk citra-citra umum dan hasil citra scan kepala MRI (Kalaiselvi, 2017). Di paper mereka, pengambangan otsu didapatkan hasil yang lebih baik dibanding dengan Sauvola, Ridler dan Calvard, Kittler dan Illingworth, dan Niblack didasarkan pada Region Non-Uniformity (RNU) untuk perhitungan evaluasi performa.

Rashmi Saini mereview delapan binerisasi citra lokal mengenai metode, konsep, kelebihan dan kekurangan. Kesimpulan dari penelitian tersebut adalah pengambangan lokal adaptif dimanfaatkan untuk pengalamatan masalah-masalah dan menangani informasi tekstual. Hasil pengambangan lokal adaptif lebih baik dari pengambangan global.

Pada artikel ini akan mencoba menggunakan metode pengambangan lokal adaptif berdasarkan rata-rata lokal piksel dan standar deviasi yaitu sauvola. Paper ini akan mencoba untuk mencari tahu pemanfaatan sauvola untuk diaplikasikan pada pengambangan di background subtraction pada kasus deteksi objek beregerak. Kontribusi dalam penelitian ini adalah belum adanya analisis mengenai pemanfaatan salah satu algoritma adaptive lokal threshold yaitu sauvola yang diimplementasikan pada kasus deteksi objek bergerak. Paper ini akan dibagi menjadi : Bagian 1. Latar belakang penelitian ini dan beberapa penelitian sebelumnya yang terkait. Bagian 2. Berisi alur diagram dan penjelasan mengenai metode sauvola dan niblack pada nilai pengambangan background subtraction. Bagian 3. Hasil eksperimen dari penggunaan pengambangan sauvola. Kemudian bagian ke 4 penarikan kesimpulan tentang penggunaan algoritma sauvola pada background subtraction apakah cukup baik dan layak berdasarkan perhitungan error.

\section{Metode Penelitian}

\section{a. Preprocessing}

Preprocessing adalah proses yang digunakan untuk meningkatkan tingkat presisi dan ketepatan dalam klasifikasi yang dibuat. Menurut paper (Shameena \& Jabbar, 2014) bahwa beberapa teknik dalam preprocessing yaitu Gabor Filter, Filter Adaptif, Operasi Morfologi, Filter rerata, Normalisasi citra, Weighted median Filter, dsb.

\section{b. Background Subtraction}

Salah satu teknik pada bidang pengolahan citra dan computer vision yang bertujuan untuk mendeteksi atau mengambil foreground dari background untuk diproses lebih lanjut. Background subtraction biasanya digunakan untuk deteksi objek bergerak dengan kamera statis. Menurut (Gonzalez, 2009) jika perbedaan diantara nilai piksel hasil subtract lebih besar dari nilai threshold maka piksel akan dikategorikan bagian foreground. Formula dari background subtraction

$$
\Delta_{t}(x, y)=\left|B(x, y)-I_{t}(x, y)\right|
$$


$O_{t}(x, y)=\int_{0}^{1} \begin{gathered}\text { if abs }\left(\Delta_{t}(x, y)\right) \geq \text { Thres } \\ \text { Otherwise }\end{gathered}$

c. Sauvola Threshold

Sauvola adalah pengembangan dari algoritma niblack melalui perhitungan nilai threshold menggunakan jarak dinamis standard deviasi citra grayscale.

$$
T s_{(i, j)}=m *\left(1-k *\left(1-\frac{S_{(i, j)}}{R}\right)\right)
$$

$m$ adalah nilai rata-rata lokal dan $\mathrm{k}$ adalah nilai konstan bernilai $0.2, S_{(i, j)}$ adalah Standar Deviasi dan $R$ adalah rentang dinamis standard deviasi ( $R=128$ dengan 8bit gray level).

d. Evaluasi Hasil

Untuk perhitungan evaluasi hasil akan digunakan perhitungan error MSE (Mean Square Error) dan PSNR (Peak Signal to Noise Ratio). Menurut penelitian (Pinki, 2016) ketika posisi PSNR meningkat atau bernilai tinggi dan posisi MSE menurun atau bernilai kecil maka citra yang didapat sangat halus untuk persepsi mata. Berikut adalah formula untuk MSE, yaitu :

$$
M S E=\frac{\sum_{a=0}^{x-1} \sum_{b=0}^{y-1}\left(M_{(a, b)}-N_{(a, b)}\right)}{x * y}
$$

$M_{(a, b)}$ adalah Nilai citra hasil threshold dan $N_{(a, b)}$ adalah citra referensi. PSNR menurut (Pinki, 2016) adalah rasio kemungkinan maksimum power sinyal menjadi kemungkinan maksimum power noise. Berikut akan diikuti oleh formula untuk PSNR, yaitu :

$$
P S N R=10 \log _{10} \frac{\operatorname{Max} 2}{M S E}
$$

$M x_{i}$ adalah nilai piksel maksimum dalam sebuah citra. Biasanya diberi nilai 255.

\section{e. Metode yang diusulkan}

Metode yang diusulkan dalam penelitian ini adalah penggunaan sauvola pada threshold background subtraction. Untuk flowchart pada metode penelitian ini dapat dilihat pada gambar 1 .

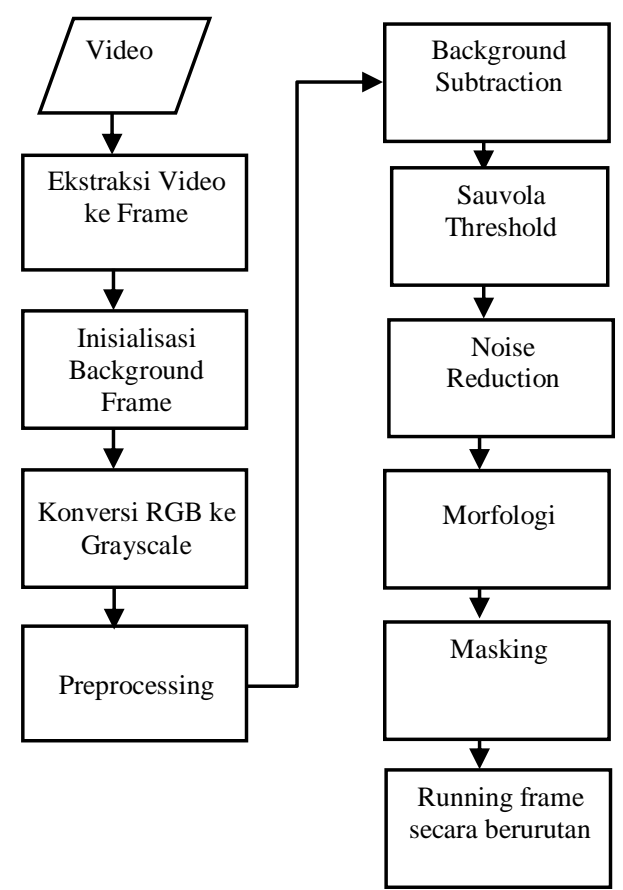

Gambar 1. Alur Metode Penelitian

Langkah-langkah yang digunakan dalam metode penelitian ini :

1) Ekstraksi video menjadi beberapa frame. Setiap video diatur menjadi 30 frame.

2) Inisialisasi frame pertama menjadi background. Setiap video akan diekstraksi mejadi 30 frame, dan di frame pertama akan digunakan sebagai frame background.

3) Konversi per frame RGB menjadi grayscale.

4) Melakukan proses preprocessing dengan menggunakan median filter. Berikut algoritma untuk median filter $f(x, y)=$ median $\{f(x-T, y-T), \ldots$, $f(x-T, y+T), \ldots, f(x, y), \ldots, f(x+$ $T, y-T, \ldots, f(x+T, y+T)\}$

5) Mengurangi citra objek dengan citra background menggunakan persamaan 1.

6) Pemanfaatan sauvola pada nilai threshold di background subtraction dengan menggunakan persamaan (2). Gunakan perbandingan pada persamaan (1). jika hasil subtraction lebih besar dibanding threshold maka bernilai 1 jika sebaliknya bernilai 0 .

$$
\begin{gathered}
\Delta_{t}(x, y)=\left|B(x, y)-I_{t}(x, y)\right| \\
T s_{(i, j)}=m *\left(1-k *\left(1-\frac{S_{(i, j)}}{R}\right)\right) \\
(i, j) \subseteq(x, y)
\end{gathered}
$$




$$
O_{t}(x, y)=\int_{0}^{1} \begin{gathered}
\text { if abs }\left(\Delta_{t}(x, y)\right) \geq T s(x, y) \\
\text { Otherwise }
\end{gathered}
$$

$T s_{(i, j)}$ adalah hasil threshold piksel ketetanggaan. $O_{t}(\mathrm{x}, \mathrm{y})$ adalah hasil pengambangan. $S_{(i, j)}$ adalah standar deviasi piksel ketetanggaan. Setelah dilakukan proses perhitungan threshold dengan sauvola, maka bandingkan hasil subtraction dengan hasil threshold sauvola.

7) Penghilangan noise pada hasil pengambangan sauvola dan niblack dengan masing-masing nilai yang berbeda pada setiap video.

8) Memanfaatkan salah satu metode morfologi untuk menambahkan piksel antar objek.

9) Membuat masking setelah melakukan proses morfologi. Hasil setiap frame yang telah diberikan mask kemudian dijalankan frame per frame secara berurutan.

\section{Hasil dan Pembahasan}

Penelitian ini menggunakan 4 video yang terdiri dari 3 video indoor dan 1 video outdoor. Apikasi yang digunakan yaitu matlab 2015a dengan dukungan hardware Intel core i5 @ $3.20 \mathrm{GHz}$ dan RAM 8 gb.

Menyesuiakan dari metode penelitian, terdapat 3 langkah utama dalam penelitian ini yaitu, background subtraction, pengambangan sauvola, dan hasil akhir berupa frame yang telah diberi mask. Pada tabel 1 dapat dilihat hasil dari background subtraction. Hasil pengurangan antara setiap frame objek dengan frame background

\section{Tabel 1. Hasil Background subtraction}

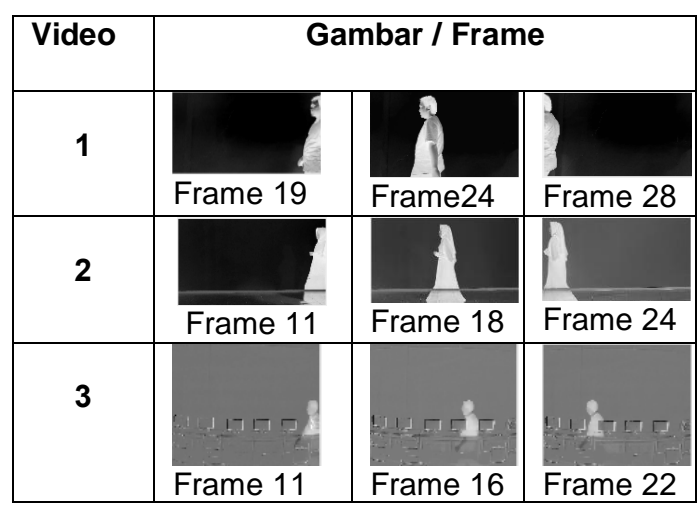

Pada tabel 2 merupakan hasil dari pengambangan sauvola dengan menggunakan nilai $k=0,2$ (default $)$.

Tabel 2. Hasil pengambangan sauvola

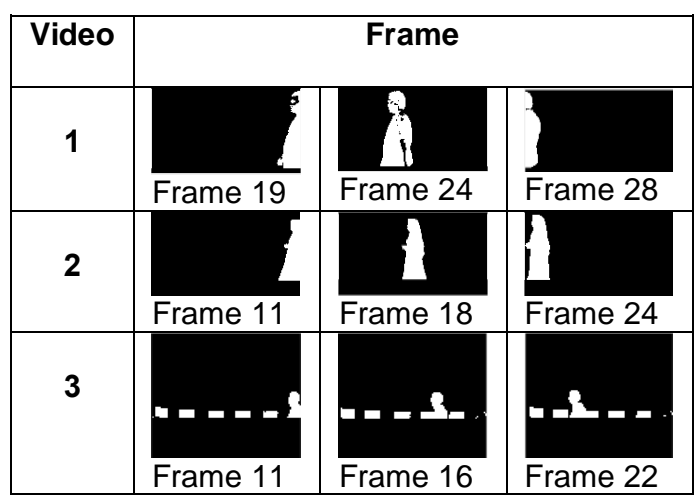

Untuk hasil akhir setelah proses threshold dapat dilihat pada tabel 3. Pada frame 11 terlihat bahwa hasil masking terlihat kurang baik dikarenakan melebihi objek. Hal ini disebabkan karena proses penghilangan noise kurang sempurna. Namun secara keseluruhan cukup baik.

Tabel 3. Hasil masking sampel frame

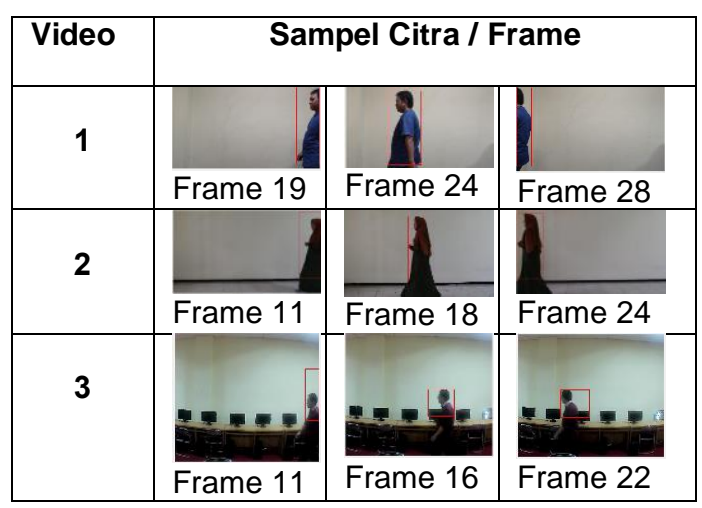

Untuk tahap evaluasi menggunakan MSE dan PSNR dengan relasi mengikuti paper (Pinki, 2016) menerangkan bahwa perbandingan saat MSE rendah atau mendekati 0 maka PSNR menjadi $\infty$. Untuk tabel rata-rata MSE dan PSNR ditunjukkan pada tabel 5 dan tabel sample hasil setiap frame dapat dilihat pada tabel 4 .

Tabel 4. Sampel hasil MSE / PSNR per frame

\begin{tabular}{|c|c|c|c|}
\hline Sample & \multicolumn{3}{|c|}{ MSE / PSNR ( / Frame) } \\
\cline { 2 - 4 } Videos & 10 & 15 & 21 \\
\hline 1 & $0,0011 /$ & $0,0011 /$ & $0,0011 /$ \\
& 53,3225 & 53,3225 & 53,3198 \\
\hline 2 & $0,0434 /$ & $0,1708 /$ & $0,1292 /$ \\
\hline
\end{tabular}




\begin{tabular}{|l|l|l|l|}
\hline & 38,2614 & 31,7397 & 32,9504 \\
\hline 3 & $0,4793 /$ & $0,4272 /$ & $0,5901 /$ \\
& 27,2584 & 27,7585 & 26,3559 \\
\hline
\end{tabular}

Tabel 5. Rata-rata MSE / PSNR seluruh frame video

\begin{tabular}{|c|c|}
\hline Sample Videos & $\begin{array}{c}\text { Average } \\
\text { MSE / PSNR }\end{array}$ \\
\hline Video 1 & $0,0011 / 53,6653$ \\
\hline Video 2 & $0,0855 / 33,3564$ \\
\hline Video 3 & $1,2796 / 25,3933$ \\
\hline
\end{tabular}

Dapat dilihat pada rata-rata nilai MSE dan PSNR mengindikasikan bahwa hasil thresholding yang didapat sauvola cukup baik untuk dijadikan sebagai acuan nilai threshold background subtraction.

\section{Kesimpulan}

Kesimpulan yang dapat diambil dalam penelitian ini adalah untuk mencari tahu bahwa sauvola dapat digunakan sebagai nilai threshold dalam background subtraction. Sesuai dengan hasil yang didapat bahwa sauvola cukup baik digunakan sebagai nilai threshold dengan rata-rata terbaik dalam MSE 0,0011 dan PSNR 53,6653.

\section{Referensi}

Das, D., \& Saharia, S. (2014). Implementation and Performance Evaluation of Background Subtraction Algorithms. International Journal on Computational Science \& Applications, 4(2), 49-55. https://doi.org/10.5121 /ijcsa.2014.4206
Ghaye, J., Kamat, M. A., Corbino-Giunta, L., Silacci, P., Vergères, G., De Micheli, G., \& Carrara, S. (2013). Image thresholding techniques for localization of sub-resolution fluorescent biomarkers. Cytometry Part A, 83(11), 1001-1016. https://doi.org/ 10.1002/cyto.a.22345

Kalaiselvi, T. (2017). a Comparative Study on Thresholding Techniques for Gray Image Binarization. International Journal of Advanced Research in Computer Science, 8(7), 1168-1172. https://doi.org/10.26483/ijarcs.v8i7.451 0

N, S., \& S, V. (2016). Image Segmentation By Using Thresholding Techniques For Medical Images. Computer Science \& Engineering: An International Journal, 6(1), 1-13. https://doi.org/10.5121/ cseij.2016.6101

Pinki, R. M. (2016). Estimation of the Image Quality under Different Distortions. International Journal Of Engineering And Computer Science, 5(17291), 17291-17296.

https://doi.org/10.18535/ijecs/v5i7.20

Shameena, N., \& Jabbar, R. (2014). A Study of Preprocessing and Segmentation Techniques on Cardiac Medical Images. International Journal of Engineering Research and Technology (IJERT), 3(4), 336-341. https://doi.org/10.1177/174701611771 1971 